\title{
Optimal Cutoff Level of Fecal Calprotectin for Detecting Small Bowel Inflammation in Crohn's Disease
}

\author{
Eun Soo Kim \\ Division of Gastroenterology, Department of Internal Medicine, School of Medicine, Kyungpook National University, Daegu, Korea
}

\author{
Corresponding Author \\ Eun Soo Kim \\ ORCID https://orcid.org/0000-0003-0806-9136 \\ E-mail dandy813@hanmail.net
}

\author{
See "Diagnostic Accuracy of Fecal Calprotectin for the Detection of Small Bowel Crohn's \\ Disease through Capsule Endoscopy: An Updated Meta-Analysis and Systematic Re- \\ view." by Eun Suk Jung, et al. on page 732, Vol. 15, No. 5, 2021
}

Crohn's disease $(\mathrm{CD})$ is a longstanding inflammatory disorder of the gastrointestinal tract (GIT) that often requires the life-long medical care. ${ }^{1}$ It is categorized by disease-involved location as ileal (L1), colonic (L2), and ileo-colonic (L3) through the Montreal classification. ${ }^{2}$ Small bowel lesion is found in up to $30 \%$ of CD patients. ${ }^{1}$ Considering that main symptoms of CD such as abdominal pain and diarrhea are not disease-specific, it is a great challenge for clinicians to correctly differentiate $\mathrm{CD}$ from other functional disorders in symptomatic patients without alarm signs. It is even more difficult when patients have lesions in the small bowel where the endoscopy is not able to reach. Noninvasive biomarkers are helpful in these patients in navigating the diagnostic process.

In contrast to blood-based indicators of inflammation including C-reactive protein and erythrocyte sedimentation rate which are nonspecific for the GIT and whose values are significantly affected by other inflammatory conditions, fecal calprotectin (FC) is a good biomarker for intestinal inflammation as this has the merit of greater specificity for the GIT. ${ }^{3,4}$ However, the role of FC is not well established in small bowel CD compared with colonic diseases like ulcerative colitis or colonic location of CD. ${ }^{5}$

In the current issue, Jung et al. $^{6}$ reported meta-analysis and systematic review with 14 studies on diagnostic accuracy of FC for detection of small bowel CD through capsule endoscopy. They suggested FC $100 \mu \mathrm{g} / \mathrm{g}$ as the optimal diagnostic cutoff for diagnosis of small bowel $\mathrm{CD}$ as the diagnostic odds ratio (DOR) is the highest at $100 \mu \mathrm{g} / \mathrm{g}$ (DOR 7.89 , sensitivity 0.73 , specificity 0.73 ) compared with $50 \mu \mathrm{g} / \mathrm{g}$ (DOR 5.52, sensitivity 0.83 , and specificity
0.5 ) and $200 \mu \mathrm{g} / \mathrm{g}$ (DOR 7.21, sensitivity 0.5 , and specificity 0.88). Furthermore, FC level of $100 \mu \mathrm{g} / \mathrm{g}$ showed better diagnostic accuracy (DOR 10.07, sensitivity 0.76 , and specificity 0.75 ) in the subgroup of patients with a negative ileocolonoscopy in whom inflammatory biomarkers would be more needed as a triage tool for accurate diagnosis of small bowel CD. The strong point of this study would be the latest meta-analysis which has been updated from previous one in 2016 by adding seven studies on diagnostic value of FC in detection of small bowel CD. The results of the study are clinically more relevant in Asian countries like Korea where small bowel location of $\mathrm{CD}$ is more common than in Western countries. ${ }^{8,9}$

A previous meta-analysis with seven studies suggested FC $50 \mu \mathrm{g} / \mathrm{g}$ as a cutoff value for the detection of small bowel CD in suspected patients with normal ileo-colonoscopy because it showed the highest sensitivity (0.87) and excellent negative predictive value of $91.8 \%{ }^{7}$ This means that 13 out of 100 patients with small bowel CD show negative result in FC test; false negative rate is low to 0.13. Thus, the chance of positive diagnosis is very low in negative FC. However, this high sensitivity is at the cost of decreasing the test specificity and the positive predictive value. FC cutoff $50 \mu \mathrm{g} / \mathrm{g}$ showed low specificity of 0.55 and low positive predictive value of $34.5 \%$ which means that 45 out of 100 patients without small bowel CD have positive result in FC test (false positive rate 0.45 ). Hence, approximately half of patients without disease would undergo unnecessary further examinations or would be treated as CD. In contrast, increasing cutoff value to $200 \mu \mathrm{g} / \mathrm{g}$ showed high specificity of 0.94 (low false positive rate of 6\%) but low 
sensitivity of 0.42 (high false negative rate of $58 \%$ ). These results were in line with those in Jung et al.'s study showing the highest sensitivity with the lowest specificity at FC 50 $\mu \mathrm{g} / \mathrm{g}$ and the highest specificity with the lowest sensitivity at FC $200 \mu \mathrm{g} / \mathrm{g} .{ }^{6}$

Therefore, FC level of $100 \mu \mathrm{g} / \mathrm{g}$ is a well-balanced value providing the highest DOR with equally moderate levels of sensitivity (0.73) and specificity (0.73) for the diagnosis of small bowel CD.

Although $100 \mu \mathrm{g} / \mathrm{g}$ is the optimal cutoff of FC test, we should keep in mind that around a quarter of suspected patients taking FC test will have false positive or false negative results. Also, we need to understand the limitations of FC test including within-stool and within-day variability in FC. Infectious colitis, intestinal neoplasms, cirrhosis, diverticulitis, and drugs such as nonsteroidal anti-inflammatories and proton pump inhibitors may increase FC levels. ${ }^{3}$ Patients need to be counseled regarding these issues of FC test. In patients with negative results, they need to be followed up for their symptom changes or monitored with repeated biomarkers if needed. Positive results should lead to taking further investigations such as capsule endoscopy or cross-sectional imaging for the confirmation of small bowel CD.

\section{CONFLICTS OF INTEREST}

No potential conflict of interest relevant to this article was reported.

\section{ORCID}

Eun Soo Kim

https://orcid.org/0000-0003-0806-9136

\section{REFERENCES}

1. Torres J, Mehandru S, Colombel JF, Peyrin-Biroulet L. Crohn's disease. Lancet 2017;389:1741-1755.

2. Satsangi J, Silverberg MS, Vermeire S, Colombel JF. The Montreal classification of inflammatory bowel disease: controversies, consensus, and implications. Gut 2006;55:749753.

3. Ma C, Battat R, Parker CE, Khanna R, Jairath V, Feagan BG. Update on C-reactive protein and fecal calprotectin: are they accurate measures of disease activity in Crohn's disease? Expert Rev Gastroenterol Hepatol 2019;13:319-330.

4. Hiraoka S, Takashima S, Inokuchi T, et al. The novel latex agglutination turbidimetric immunoassay system for simultaneous measurements of calprotectin and hemoglobin in feces. Intest Res 2019;17:202-209.

5. Simon EG, Wardle R, Thi AA, Eldridge J, Samuel S, Moran GW. Does fecal calprotectin equally and accurately measure disease activity in small bowel and large bowel Crohn's disease? A systematic review. Intest Res 2019;17:160-170.

6. Jung ES, Lee SP, Kae SH, Kim JH, Kim HS, Jang HJ. Diagnostic accuracy of fecal calprotectin for the detection of small bowel Crohn's disease through capsule endoscopy: an updated meta-analysis and systematic review. Gut Liver 2021;15:732-741.

7. Kopylov U, Yung DE, Engel T, et al. Fecal calprotectin for the prediction of small-bowel Crohn's disease by capsule endoscopy: a systematic review and meta-analysis. Eur J Gastroenterol Hepatol 2016;28:1137-1144.

8. Ye BD, Hong SN, Seo SI, et al. Changes in the Long-term prognosis of Crohn's disease between 1986 and 2015: the population-based Songpa-Kangdong inflammatory bowel disease cohort study. Gut Liver. Epub 2021 Jun 22. https:// doi.org/10.5009/gnl210044.

9. Kaibullayeva J, Ualiyeva A, Oshibayeva A, Dushpanova A, Marshall JK. Prevalence and patient awareness of inflammatory bowel disease in Kazakhstan: a cross-sectional study. Intest Res 2020;18:430-437. 